\title{
Os significados das práticas de promoção da saúde na infância: estudo do cotidiano escolar pelo desenho
}

\author{
The significance of health promotion practices in childhood: \\ a study of daily school life through drawing
}

Eduardo Alexander Júlio César Fonseca Lucas (https://orcid.org/0000-0001-6638-0788) ${ }^{1}$

Rubens de Camargo Ferreira Adorno (https://orcid.org/0000-0002-8772-3222) ${ }^{2}$

Antonio Eduardo Vieira dos Santos (https://orcid.org/0000-0002-4326-0211) ${ }^{3}$

Maria Antonieta Rubio Tyrrell (https://orcid.org/0000-0002-1885-6865) ${ }^{4}$

Vera Lucia Rabello de Castro Halfoun (https://orcid.org/0000-0002-0311-9379) ${ }^{1}$

\footnotetext{
${ }^{1}$ Faculdade de Medicina, Universidade Federal do Rio de Janeiro. R. Prof. Rodolpho Paulo Rocco 325, Cidade Universitária. 21941617 Rio de Janeiro RJ Brasil. eduardoalexander@ gmail.com

${ }^{2}$ Faculdade de Saúde Pública, Universidade de São Paulo. São Paulo SP Brasil.

${ }^{3}$ Faculdade de Enfermagem, Universidade do Estado do Rio de Janeiro. Rio de Janeiro RJ Brasil.

${ }^{4}$ Universidade Federal do Rio de Janeiro. Rio de Janeiro RJ Brasil.
}

\begin{abstract}
The scope of this paper was to describe the health promotion practices developed in a community school in the municipality of Rio de Janeiro in the light of public policies and the school culture. It sought to analyze the significance attributed by the students to these practices and discuss the model of care and health promotion practices developed at school, based on the meanings attributed to such practices by the subjects under study. The qualitative and ethnographic approach supported by Geertz facilitated an understanding of the significance emerging around the health issue. The results demonstrated the incorporation of health promotion actions in daily school life, their interface with sectorial policies, and the central importance of these actions in normative aspects. The significance reproduced medical-sanitary clichés portraying the social spaces, the material resources, the procedures involved and the social actors in these actions. The influence of local culture, habits and lifestyles in the construction of the concept of health in the community studied is highlighted.
\end{abstract}

Key words Health in School, Child Health, Pediatric Nursing, Primary Health Care
Resumo Esse artigo objetivou descrever as práticas de promoção da saúde desenvolvidas numa comunidade escolar do Município do Rio de Janeiro à luz das políticas públicas e da cultura escolar; analisar os significados atribuídos pelos escolares às práticas de promoção da saúde, a partir do cotidiano da comunidade; discutir o modelo de atenção e as práticas de promoção da saúde desenvolvidas na escola, a partir dos significados atribuídos por crianças em idade escolar. A abordagem qualitativa e etnográfica apoiada em Geertz permitiu compreender os significados emergentes acerca do tema saúde. Os resultados demonstraram a incorporação das ações de promoção da saúde no cotidiano escolar, sua interface com as politicas setoriais, e a centralidade dessas ações em aspectos normativos. Os significados reproduziram clichês médico-sanitários retratando os espaços sociais, recursos materiais, procedimentos envolvidos e atores sociais dessas ações. Destaca-se a influência da cultura local, hábitos/modos de vida na construção do conceito de saúde na coletividade estudada.

Palavras-chave Saúde Escolar, Saúde da Criança, Enfermagem Pediátrica, Atenção Primária à Saúde 


\section{Introdução}

O discurso oficial do Estado é normalmente "traduzido" a partir dos contextos de vida e diferentes percepções que vários indivíduos podem ter sobre um mesmo problema relacionado à saúde. Essa problemática tona-se particularmente especial de ser discutida quando direcionada à população infantil, pois muito do que se percebe enquanto compreensão do que seja saúde na vida adulta foi culturalmente apreendido na infância. Questões podem ser suscitadas tomando como base os significados que os escolares moradores de comunidades urbanas carentes atribuem ao tema "saúde"; e, de que forma os modelos de atenção à saúde são compreendidos por essa parcela da população. Os objetivos desta investigação foram: descrever as práticas de promoção da saúde desenvolvidas numa comunidade escolar do Município do Rio de Janeiro à luz das políticas públicas e da cultura escolar; analisar os significados atribuídos pelos escolares às práticas de promoção da saúde, a partir do cotidiano da comunidade; discutir o modelo de atenção e as práticas de promoção da saúde desenvolvidas na escola, a partir dos significados atribuídos por crianças em idade escolar.

O referencial teórico utilizado está vinculado aos conceitos de cultura de Geertz'; de promoção da saúde (Organização Mundial de Saúde - OMS, 1990) à luz da Iniciativa Escola Promotora de Saúde (IEPS) (Organização Pan-Americana de Saúde - OPAS) ${ }^{2}$; bem como os pressupostos de Sarmento ${ }^{3}$ acerca dos desenhos infantis enquanto objetos simbólicos. Dada a complexidade e amplitude destes temas propõe-se aqui tão somente tecer considerações para uma aproximação com os conceitos abordados. Em razão da especificidade do universo conceitual adotado foram utilizadas também as bases programáticas do Programa Saúde na Escola (PSE) ${ }^{4,5}$. Numa perspectiva semiótica, "o homem é um animal amarrado a teias de significados que ele mesmo teceu". A cultura deve ser entendida como sendo "essas teias e a sua análise, uma ciência interpretativa à procura do significado"1. Todos os elementos da cultura analisada deverão ser entendidos à luz da realidade cultural e os "observadores situados" devem entender como as coisas simplesmente são, mesmo que as vejam de forma diferentes, valorizando o contexto cultural do qual eles vêm, do qual extraem suas percepções e princípios ${ }^{1}$.

A dificuldade de se encontrar definição para o conceito de saúde não é atual, mas parece advir desde a antiga Grécia ${ }^{6}$. Do ponto de vista episte- mológico o conhecimento sobre esse tema é muito complexo e parece estar vinculado ao contexto socioeconômico e político-cultural de cada sociedade, sendo diferenciado de acordo com cada época e lugar ${ }^{7}$. O limite entre o normal e o patológico varia muito entre as organizações sociais8. Concepções dominantes assumiram status de categorias universais, passando a ser arbitradas, nos domínios institucionais, aos doentes e suas famílias, assim como sobre outras concepções sociais acerca do processo saúde-doença para objetivar e reduzir compreensão do funcionamento do organismo à metáfora do corpo humano como "máquina"s,9. Sob esse aspecto, são desconsiderados os componentes que relativizam a verdade cientifica da medicina, nos quais se projetam os princípios para legitimar os modos de dominação. Ademais, a concepção tradicional da doença se apoia no princípio dos "contrários" no qual a doença enquanto categoria social é vista como uma ruptura do equilíbrio natural e reestabelecer esse equilíbrio é a base da medicina ocidental ${ }^{8,9}$.

$\mathrm{Na}$ escola a utilização dos conceitos propostos pela IEPS da OPAS/OMS se faz pertinente, pois viabiliza a implantação de políticas de saúde voltadas para a escola, apoiadas na visão global do ser humano, inserido no contexto familiar e comunitário. Isto fomenta o desenvolvimento humano, promovendo a aquisição de habilidades para a vida saudável. A promoção da saúde escolar, segundo essa iniciativa, tem três vertentes: educação para saúde com enfoque integral; criação/manutenção de ambientes físicos e psicossociais saudáveis e provisão de serviços de saúde ${ }^{2}$. Nessa estratégia é fundamental a participação da comunidade em todas as etapas do trabalho e nas políticas de educação básica e saúde, nos três níveis de governo ${ }^{4,5}$, i.e., "com" a população e não "para" a população, possibilitando o fortalecimento de sua autonomia, resgatando-se valores de consciência social, cidadania, solidariedade e direitos humanos. Assim, a promoção da saúde é compreendida como um avanço pois desloca o foco individual para dimensão coletiva, como a escola e o meio ambiente ${ }^{2}$. A IEPS possibilita a revisão das práticas higienistas ampliando a concepção da saúde escolar para a visão integral, interdisciplinar visando desenvolver conhecimentos para o autocuidado. Fomenta análise e reflexão sobre as condições sociais e estilos de viver, contribuindo na melhoria da qualidade de vida e maior participação da comunidade na tomada de decisões².

Como desdobramento da IEPS, o Programa Saúde na Escola (PSE) tem relevância no desen- 
volvimento integral das comunidades onde está inserido e objetiva proporcionar a participação comunitária em projetos integrados que articulem saúde e educação no contexto do Sistema Único de Saúde (SUS), que são essenciais para enfrentamento das vulnerabilidades das crianças/ famílias ${ }^{4,5}$. As ações do PSE devem estar inseridas no projeto político pedagógico da escola, à luz da diversidade sociocultural para promover a saúde e a cultura da paz, a prevenção de agravos e a comunicação entre escolas e unidades de saúde ${ }^{4,5}$. As diretrizes do PSE incluem: descentralização e respeito à autonomia federativa; integração das redes públicas de ensino e saúde; territorialidade; interdisciplinaridade; intersetorialidade; integralidade; cuidado ao longo do tempo; controle social; monitoramento e avaliação permanentes. O PSE prevê que o planejamento das ações considere o contexto social, diagnóstico local e capacidade operativa em saúde abarcando atividades de promoção, prevenção e atenção à saúde, desenvolvidas articuladamente com a escola, por meio de três componentes: avaliação clínica/psicossocial (incluindo antropometria, imunizações, saúde ocular, nutrição, dentre outros); promoção da saúde/prevenção de danos (enfocando atividades físicas, saúde sexual/reprodutiva, prevenção/ controle do uso de drogas/álcool/tabaco, dentre outros); e, formação/educação permanente em saúde (que envolve a gestão do próprio PSE). Cada componente é contemplado com linhas de ação que são avaliadas pelo conjunto de metas e englobam questões de ordem biológica, mas também relativas à interação comunitária, incluindo temas como bullying e sustentabilidade ambiental ${ }^{4}$.

Em relação aos desenhos, cumpre destacar que são artefatos sociais da geração infantil que expressam as condições culturais e sociais de inserção das crianças em cada contexto de vida. O grafismo infantil adquire a complexidade e a densidade da sua capacidade comunicativa pelo fato de incorporar uma imbricada articulação de várias fontes de produção cultural. A compreensão dos desenhos como objetos simbólicos impõe análise semiológica e interpretação polissêmica atentas às diversas perspectivas. A primeira engloba os aspectos culturais, linguísticos e sociais e a segunda engendra nas formas e cores, como o produto singular da criação de um sujeito concreto - a pessoa da criança que o desenhou. Os desenhos ativam processos de apropriação e representação do mundo, vislumbrados por códigos culturais, nos quais se espelha uma historicidade das formas materializadas graficamente variando conforme o espaço social, o tempo e a sua inserção sociocultural ${ }^{3}$. Ao enfatizar a "teia de representações simbólicas” em que se insere o processo de desenvolvimento sociocultural da criança, é possível interpretar os desenhos como atos de criação cultural que evidenciam, além de aspectos biopsicológicos, os elementos específicos de ação social das crianças ${ }^{10}$. Por intermédio dos desenhos se exploram os limites da linguagem, sendo esses não apenas um modo de inscrição do mundo na superfície do papel, mas o momento de sua inteligibilidade. Os desenhos, enquanto produções simbólicas, são meios de exploração da realidade e dos processos que constituem a sua compreensão ${ }^{3}$. A análise sociológica dos processos envolvidos na elaboração dos desenhos vislumbra os meios disponíveis para a realização dessa atividade, as rotinas estabelecidas, as práticas institucionais (hábitos apreendidos na família, escola, ou outros espaços), as relações sociais (estabelecidas no momento da realização do desenho), o gesto gráfico e dos seus suportes físicos - o lápis de cor, o papel, entre outros elementos $^{3}$. A cultura produzida para as crianças é analisada a partir de três dimensões: a cultura produzida pelas grandes corporações internacionais, denominada "Kindercultura" ou "cultura popular"; a cultura escolar que compreende os traços culturais universalizantes produzidos nesse universo institucional; e, a cultura produzida pelas crianças, que se manifesta pela reinterpretação ativa dos artefatos/traços culturais das próprias crianças. Sob essas condições a produção dos desenhos ocorre num universo saturado de configurações visuais preexistentes, constituído por imagens projetadas influenciadas por desenhos animados, programas televisivos, livros, jogos infantis/brinquedos, e no geral, pelas corporações da indústria midiática oriundos da kindercultura ${ }^{11}$.

\section{Método}

Segundo Minayo ${ }^{12}$ este estudo possui abordagem qualitativa. Foi utilizado um enfoque etnográfico para compreender o universo de significados, valores e atitudes dos sujeitos envolvidos no contexto social observado. Seu valor reside na tentativa de capturar a acepção com que o grupo estudado interpreta suas próprias atitudes ${ }^{13}$. Com a etnografia pode-se compreender o contexto escolar, sob o ponto de vista dos próprios atores sociais, buscando entender holisticamente a forma de vida de um determinado grupo social, 
basilada no interacionismo simbólico como marco conceitua ${ }^{13}$. Ao escolher a escola como cenário da investigação, entende-se que neste espaço social a cultura local e os diferentes saberes se entrecruzam, favorecendo a criação e recriação de formas de pensar, agir e compreender o mundo. A cultura, na perspectiva antropológica, torna-se o contexto sobre o qual se desenvolvem os fatos sociais e as ações humanas e nada deve ser interpretado e analisado fora desta dimensão $0^{13}$. O pensar pode ser definido como um tráfego de símbolos significantes tais como palavras, gestos, sons, desenhos, dentre outros elementos utilizados para imprimir um significado à experiência ${ }^{1}$.

Esta pesquisa foi do tipo estudo de caso, pois se fundamenta na concepção de que a análise de uma determinada parte de um universo possibilita a compreensão da generalidade do mesmo. A ênfase na totalidade e multiplicidade das dimensões do problema permitiu a focalização dos significados atribuídos às práticas de promoção da saúde como fenômeno complexo, multifacetado e contextualizado ${ }^{14}$. Os instrumentos escolhidos para coleta de dados foram: dois formulários de coleta dos desenhos e informações complementares acompanhados da solicitação para que o escolar fizesse um desenho contando o que o mesmo entende sobre saúde/práticas de promoção da saúde desenvolvidas na escola (em seguida foram orientados a expressarem o significado dos desenhos elaborados); formulário de entrevista não diretiva; questionário de avaliação sociodemográfica, e; roteiro de observação participante para registro diário das interações e atividades de campo. A utilização do desenho, na perspectiva de Sarmento ${ }^{3}$, permitiu à luz da imagística etnográfica ${ }^{8}$, a extração dos significados mais profundos das crianças que por sua característica de desenvolvimento psicossocial encontra nessa ferramenta uma excelente forma de expressão. Os desenhos foram disparadores para aquisição dos aspectos discursivos emergentes das falas dos escolares constituindo-se, como potente ferramenta projetiva para instrumentalizar a captação dos significados atribuídos às práticas de promoção à saúde ${ }^{15}$. A entrevista não diretiva foi articulada em torno da fala e repertórios emergentes dos desenhos produzidos permitindo que o escolar pudesse verbalizar sobre o que o desenho representa para ele mesmo ${ }^{16}$.

De acordo com Adorno e Castro ${ }^{17}$ o trabalho de campo exigiu o empenho interpretativo por meio da sensibilidade deslocando as falas dos depoentes do óbvio, em direção às representações simbólicas, que pudessem corporificar a experi- ência da intersubjetividade. O campo para coleta de dados foi uma escola pública de ensino fundamental, que funciona em tempo integral como Centro Integrado de Escola Pública e está localizada na comunidade de Vila Moretti no bairro de Bangu. Este bairro tem perfil socioeconômico heterogêneo cujas condições de vida da população foram deterioradas pela favelização e violência urbana. No território há também uma Creche $\mathrm{Mu}$ nicipal, um Espaço de Desenvolvimento Infantil e um Centro Municipal de Saúde. A comunidade não teve uma estruturação urbana planejada e a topografia inclinada dificulta acesso/circulação dos moradores. Os domicílios são servidos por saneamento básico e coleta de lixo, com constantes falhas de oferta/abastecimento. Os participantes foram 95 escolares ( 49 meninas e 46 meninos), na faixa etária de seis a doze anos. A maioria foi declarada pelos pais como parda (43\%) ou negra (15\%) e pertencente às famílias de classes econômicas C (59\%) e D (26\%). Os escolares participaram do estudo com autorização dos responsáveis mediante assinatura do Termo de Consentimento Livre e Esclarecido, e ainda por livre vontade, pois na subjetividade do estudo se fez importante a imersão espontânea do escolar para o êxito esperado. Para valorizar a autonomia das crianças foi obtido o assentimento mediante a aquiescência/ concordância das mesmas, utilizando linguagem adequada à faixa etária. Esta pesquisa atendeu integralmente as normas éticas apontadas pelo Conselho Nacional de Saúde, que estabelece critérios para as pesquisas envolvendo seres humanos. Como homenagem, às crianças foram atribuídos nomes figurativos de pintores famosos de renome nacional e internacional. A coleta de dados que compreendeu o período de 1 ano e 10 meses foi realizada em quatro etapas a saber: inserção do pesquisador no cenário (aproximação e formação de vínculo); aplicação dos instrumentos para coleta das fontes primárias propriamente ditas; análise temática e; elaboração do relatório final. Para análise foram estruturadas duas categorias temáticas: "Práticas de Promoção da Saúde à Luz das Políticas Públicas e da Cultura Escolar"; e "Os Significados Atribuídos Pelos Escolares às Práticas de Promoção da Saúde e o Cotidiano da Comunidade Escolar". Destas emergiram três subcategorias: "Significados concernentes ao modelo biomédico"; "Significados concernentes ao modelo higienista", e "Significados concernentes ao modelo sociocultural pautado nos determinantes sociais da saúde". Essa categorização teve como base os temas emergentes da observação de campo, produções simbólicas (desenhos) e narra- 
tivas dos escolares que descreveram os significados atribuídos aos seus desenhos.

\section{Resultados}

\section{Práticas de promoção da saúde à luz das políticas públicas e da cultura escolar}

Os resultados dessa categoria trazem a reflexão de que, no contexto da comunidade escolar de Vila Moretti, as práticas de promoção de saúde são articuladas tanto do ponto de vista programático, como do contexto da cultura local e da própria escola. Contudo a implantação do PSE se encontra fragilizada em relação aos objetivos e diretrizes do programa no que diz respeito à integralidade; controle social; longitudinalidade, monitoramento e avaliação permanente. $\mathrm{O}$ enfoque fragmentado e biologicista das práticas de saúde reduz seu alcance nas dimensões social, cultural, ambiental, psicológica e política. $\mathrm{Na}$ perspectiva programática são evidenciados avanços importantes na Saúde do Escolar, particularmente se considerada a efetiva implantação do PSE local, a forte adesão da direção da escola ao referido programa, as parcerias interinstitucionais e as inovações na abordagem de temas, especialmente os emergentes. Limitações são percebidas na implantação do PSE da localidade pesquisada, como sucateamento dos serviços, fragilização dos vínculos empregatícios, dificuldades de compreensão dos problemas da comunidade para além das questões biológicas, e dos aspectos curativos que visam essencialmente o controle de doenças. Tais limitações favorecem o surgimento de lacunas operacionais representadas pela ausência de discussões sobre gênero, sexualidade na adolescência, direitos reprodutivos, prevenção de infecções sexualmente transmissíveis e de acidentes na infância, enfrentamento do preconceito, entre outros. Fatores como a inserção da escola em projetos do governo municipal que favorecem a interface saúde-doença e a inserção dessa temática no projeto pedagógico da escola são importantes, mas isoladamente não conseguem dar conta do todo, considerando os fatores de ordem cultural que fragilizam a aquisição de hábitos de saúde pela comunidade. Os resultados que dão conta do primeiro objetivo desse trabalho levam à constatação de que a cultura local de Vila Moretti influencia fortemente a apreensão das práticas de promoção da saúde por parte das crianças e os pressupostos de Geertz acerca da interpretação da cultura são apropriados para compreensão das ações de saúde desenvolvidas na comunidade escolar, uma vez que são originárias das experiências dos escolares no contexto local.

Sob a ótica das bases programáticas, podemos inferir possíveis caminhos para a melhoria da implantação do PSE em Vila Moretti, considerando as experiências de implantação deste programa em outros locais. Cyrino e Pereira ${ }^{18}$ destacam a potência deste programa tanto para a quebra do paradigma do modelo biomédico como para um maior protagonismo na participação dos escolares e suas famílias. Baggio et al. ${ }^{19}$ reforçam que o PSE pode proporcionar interação entre saúde, escola e família e consequente vinculação desta última à Unidade Básica de Saúde, permeada pela interação colaborativa entre profissionais de saúde e educação. Problemas na implantação do PSE são capazes de fornecer subsídios para a compreensão de cenários, como restrita articulação na gestão dos entes federal e municipal, bem como a fragilidade na articulação entre os setores de educação e saúde ${ }^{20,21}$.

No caso de Vila Moretti, a melhoria da implantação do PSE pode estar mais ligada ao papel do Estado cuja intervenção pode ser viabilizada pelo processo de empoderamento da comunidade para transformação da sua própria realidade. Para que as ações de saúde preconizadas alcancem as reais necessidades da população local, os profissionais de saúde do PSE devem aproximar as diretrizes governamentais ao contexto da comunidade em que atuam. Nesse sentido os profissionais envolvidos na Atenção Primária à Saúde devem substituir condutas prescritivas e permitir aos usuários do PSE a aquisição de conhecimentos que favoreçam sua autonomia na tomada de decisões. Cabe a esses profissionais realizar a leitura e decodificação da realidade/ modos de vida de cada localidade para favorecer a efetivação de parcerias e troca de informações para promover estratégias de ações mais ajustadas as necessidades da coletividade. É premente que a escola crie espaços para reflexão sobre as práticas de promoção da saúde nela desenvolvidas, oportunizando à comunidade desenvolver um pensamento coletivo que objetive a integralidade das ações de saúde em detrimento de práticas reparadoras isoladas e pautadas na esfera curativa de controle biológico do corpo. Essas ações integradas de saúde poderiam, com a participação comunitária, fortalecer o controle social do SUS, há muito conclamado nas conferências de saúde, permitindo que as ações de promoção da saúde possam ser efetivamente pactuadas entre gestores, profissionais de saúde e usuários ${ }^{4}$. 


\section{Os significados atribuídos pelos escolares às práticas de promoção da saúde e o cotidiano da comunidade escolar}

\section{Significados concernentes ao modelo biomédico}

Conquanto o ambiente escolar seja por sua natureza um espaço mais propício e voltado a disseminação de conceitos relativos à promoção da saúde e prevenção de agravos, o ambiente hospitalar foi retratado de forma marcante nas produções simbólicas, enquanto compreensão dessas crianças do que seria promoção da saúde. Os resultados vislumbraram diversas instituições de saúde que desenvolvem as práticas assistenciais pautadas no paradigma curativo centrado na doença e no tecnicismo. As produções simbólicas trouxeram à tona os instrumentais relacionados aos procedimentos diagnósticos/terapêuticos, geralmente invasivos, realizados pelos profissionais de saúde e retratadas em diversos cenários da prática hospitalar, destacando procedimentos como vacinação, administração de medicamentos, práticas de educação em saúde, com destaque para a supervalorização dos recursos e aparatos tecnológicos na execução das práticas de saúde. A emergência dos atores sociais no contexto dessas produções simbólicas ocorreu a partir da perspectiva do apagamento do sujeito considerandose a influência do discurso e da prática médica na sociedade contemporânea ${ }^{8,9}$, clarificada pelo destaque dado pelas crianças nos desenhos e narrativas à equipe de saúde. A análise das produções simbólicas a partir da perspectiva da infância ${ }^{3}$ permitiu a discussão de outros aspectos emergentes como a banalização da prática de automedicação, carência de recursos humanos e superlotação das unidades de saúde. Tais situações foram retratadas tendo como substrato o contexto de vida dos escolares, que reúne, experiências vivenciadas por essas crianças nas instituições de saúde, e a incorporação do discurso midiático sobre a crítica ao modelo de atenção hegemônico veiculado nos meios de comunicação. A Figura 1 traz à tona alguns destes apontamentos.

\section{Significados concernentes ao modelo higienista}

As produções simbólicas revelaram os instrumentais relacionados às práticas de promoção da saúde realizados rotineiramente pelas crianças, geralmente ligadas às ações de cuidado corporal, como alimentação, hidratação, banho, entre outros. É necessário frisar que os resultados desse estudo evidenciaram o papel preponderante assumido pela educação formal e tradicional em relação às práticas de promoção da saúde executadas no cenário investigado.

Os resultados apontaram para a importância da educação problematizadora como ferramenta

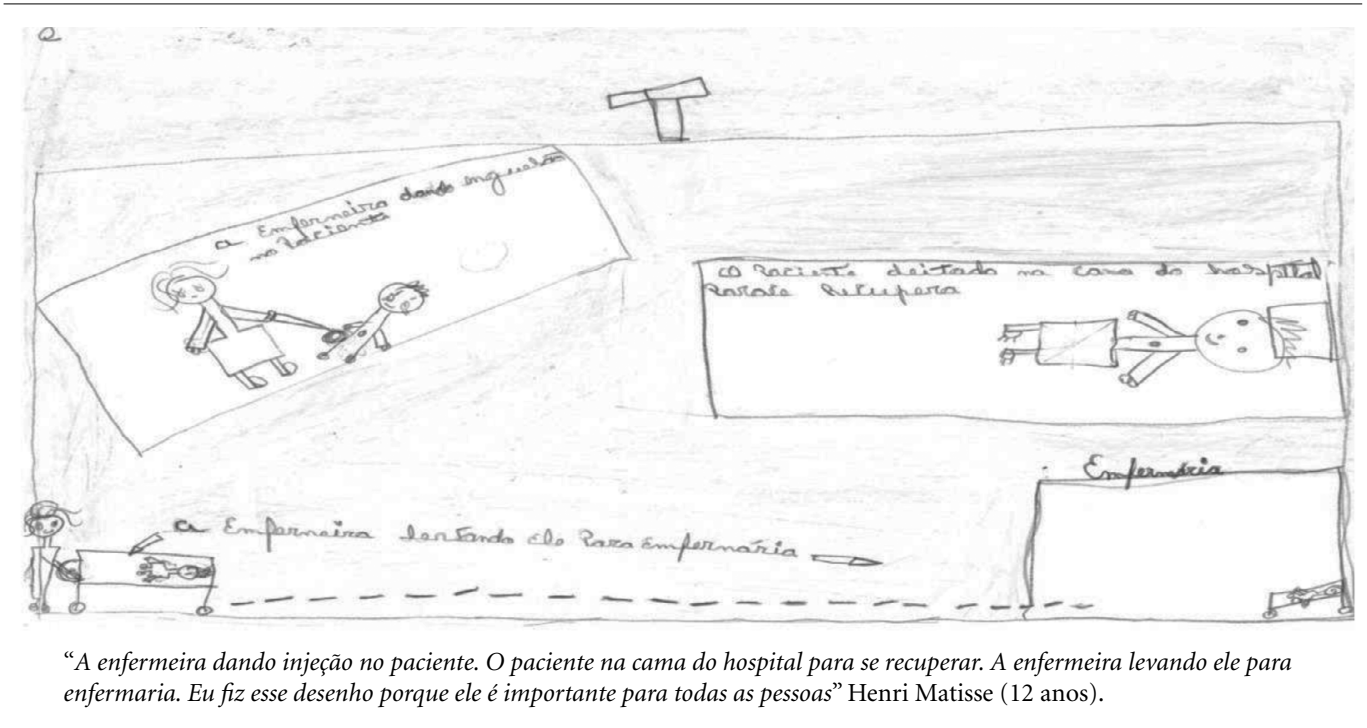

Figura 1. Produção simbólica referente ao componente humano: o reconhecimento da importância da enfermeira. 
de emancipação e cidadania, com destaque para o ensino das habilidades sociais com a finalidade de preparar as crianças para o enfretamento dos problemas da vida, conforme preconizado nas diretrizes estabelecidas pela IEPS ${ }^{4}$. A presença dos atores sociais no contexto dessas produções simbólicas ocorreu a partir da perspectiva de resgate do protagonismo do sujeito, em que pese ainda a influência do discurso higienista nesse processo, como por exemplo, o destaque dado às práticas de cuidado corporal, abordadas nos desenhos/ narrativas colocando os escolares na centralidade dessas ações de promoção da saúde. Os dados coletados reforçaram a questão da cultura medicalizante vivenciada no ambiente escolar, assim como a importância do esporte e atividades lúdicas como instrumentos socializadores. Tais situações foram retratadas, tendo como "pano de fundo" o cotidiano dessas crianças, que reúne brincadeiras que ocorrem durante o recreio, as rotinas estabelecidas pela escola, bem como a conduta assumida pela comunidade escolar nas interações sociais. A Figura 2 retrata certos aspectos que reforçam o modelo higienista.

\section{Significados concernentes ao modelo sociocultural pautado nos determinantes sociais da saúde}

No que concerne o espaço social os resultados apresentados demonstraram uma visão mais ampliada sobre saúde na medida em que abar- caram aspectos que envolvem os determinantes sociais da saúde. Diversos enfoques buscam explicar como as condições de vida, habitação e trabalho, acesso a bens e serviços tais como educação e transporte afetam a saúde das pessoas, grupos e coletividades. Destes, o modelo proposto por Dahlgren e Whitehead merece destaque pois ressalta o papel das redes comunitárias e de apoio como fundamentais na determinação das vulnerabilidades sociais ${ }^{22}$. Emergiram nesse estudo representações que retratam os ambientes que compõem a referida localidade, estabelecendo as relações existentes entre o cenário comunitário e o desenvolvimento das práticas de promoção da saúde direcionadas às condições de vida dos sujeitos de estudo. Os resultados revelaram que os instrumentais utilizados estão relacionados às interações sociais associadas principalmente às ações recreativas e foram retratadas em diversos locais do cotidiano, destacando-se o cuidado pela natureza e pelo ser humano e as brincadeiras/jogos realizados no parquinho/na praça do bairro, entre outros.

No tocante às produções de sentido que identificaram as ações de saúde desenvolvidas na perspectiva sociocultural, é importante frisar que os resultados evidenciaram o papel preponderante assumido pela participação social e autonomia dos sujeitos na construção da promoção da saúde. Destaca-se a importância da territorialização, distritalização e intersetorialidade como estraté-

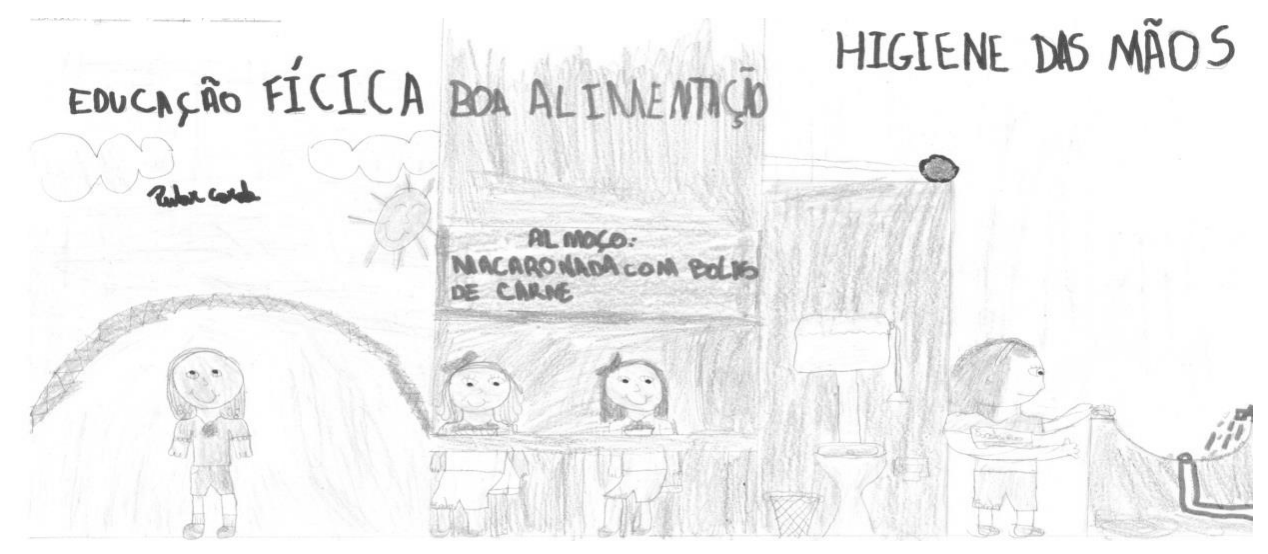

"Uma menina pulando corda na atividade fisica. Duas meninas no almoço e a alimentação faz bem pro corpo. Boa higiene das mãos, porque toda vez que a gente irmos ao banheiro devemos higienizar a mão, porque a boa limpeza faz bem pro corpo e previne doenças" Alfons Mucha (9 anos).

Figura 2. Produção simbólica referente ao cuidado centrado na perspectiva higienista. 
gias para aprimoramento dos modelos de gestão e atenção à saúde, entre outras questões ${ }^{4}$. A análise das produções simbólicas permitiu a discussão de aspectos emergentes, como a questão de gênero e a transdisciplinaridade nas práticas de saúde coletiva no contexto da comunidade escolar. Tais situações foram retratadas tendo como "foco" a realidade de Vila Moretti, que reúne os espaços frequentados pelas crianças, assim como aqueles que não o são, por dificuldade de acesso ou até mesmo inexistência na localidade. A Figura 3 exemplifica as produções de sentido que enfatizaram a importância da dimensão comunitária para as práticas de promoção da saúde.

\section{Ressignificando as práticas de promoção da saúde no cenário escolar}

As práticas de promoção da saúde significadas pelos sujeitos de estudo são estruturadas a partir de vários códigos culturais construídos pelos agentes sociais com base nas condições de vida existentes ${ }^{1,3}$. Os resultados mostraram que no centro da teia situam-se as práticas de saúde voltadas para o controle biológico do corpo e prevenção de doenças. A valorização desses aspectos em detrimento das questões socioculturais se constitui como substrato para as interações humanas que determinam o modelo de atenção hegemônico vislumbrado na realidade da comunidade pesquisada ${ }^{9}$. Na Figura 4 encon- tram-se ilustrados esses significados, formando o sistema de codificação cultural no qual elas se estruturam. Esses códigos estão amarrados uns aos outros, formando a teia de significados apreendida, juntamente com as repercussões desse modelo de atenção à saúde das crianças no contexto escolar. Partiu-se do pressuposto que esses significados são produto das interações sociais que surgem na medida em que a comunidade escolar vivencia as práticas de promoção da saúde no cenário pesquisado. Considerando o desenho como instrumento dialógico de mensuração de fenômenos sociais e representação dos pensamentos/sentimentos ${ }^{3}$, inferiu-se que o predomínio das concepções hegemônicas sobre saúde resulta do modus operandi pelo qual o PSE tem sido operacionalizado na escola pesquisada. Isto caba por refletir a fragmentação das práticas de saúde que são vivenciadas pelos escolares, reforçando a abordagem médico-centrada, prescritiva e tecnicista que privilegiam aspectos curativos, em detrimento das reais necessidades de saúde e os anseios da população. A metáfora da teia procura explicitar como os escolares reproduzem o padrão cultural a partir do emaranhado de significados sustentados pela práxis cotidiana. A centralidade do paradigma biomédico nas ações de saúde é representada pelas práticas voltadas para a prevenção de doenças e controle normativo do corpo. As produções simbólicas realçaram o papel das instituições de saúde como cerne prin-

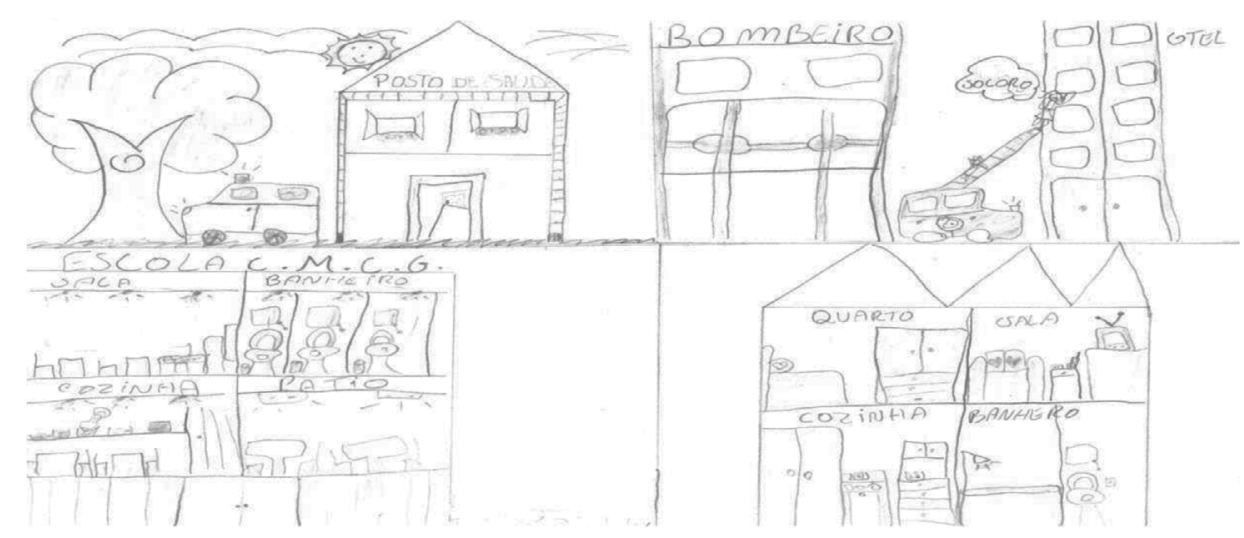

"O bombeiro significa proteção porque ele salva vidas. O posto de saúde é o local onde a gente pode buscar ajuda quando precisar. A escola significa muito aprendizado pra gente. A casa significa vida e a família" Dora Parentes (12 anos).

Figura 3. Produção simbólica referente aos equipamentos sociais. 


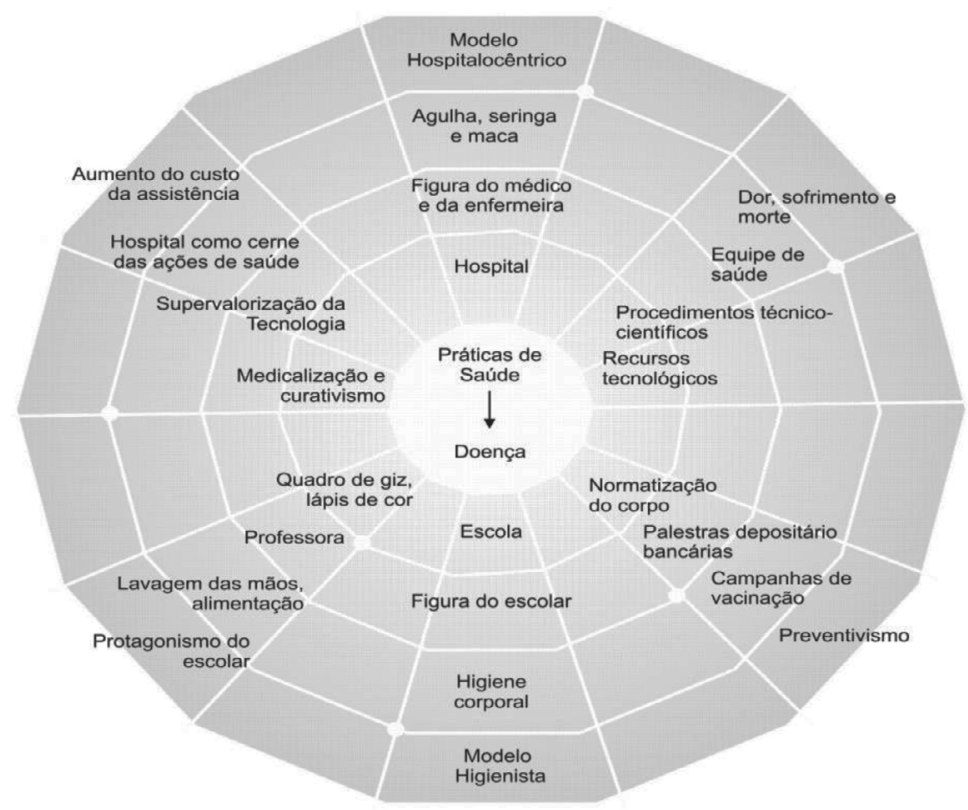

Figura 4. Significados atribuídos às práticas de promoção da saúde pelos escolares.

Fonte: Elaborado pelos autores. Adaptada utilizando-se a figura proposta por Rodrigues ${ }^{15}$.

cipal dessas práticas e a modelagem hospitalocêntrica trouxe como pano de fundo a descrição detalhada dos procedimentos técnico-científicos geralmente dolorosos/invasivos, realizados pela equipe de saúde. Essa questão permite um olhar crítico sobre a influência dos dispositivos sociais engendrados na comunidade escolar, para viabilizar o discurso dominante acerca dos mecanismos de normatização dos corpos' ${ }^{9}$. Os resultados mostraram a atuação dos profissionais de saúde no contexto do ambiente hospitalar, traduzido principalmente pela figura do médico e da enfermeira, evidenciando aspectos relacionados à medicalização dos fenômenos naturais tais como o fracasso escolar e a experiência do parto e nascimento. A evidente supervalorização da tecnologia médica, indicada como principal ferramenta para a melhoria da qualidade da assistência, expõe a dinâmica social que privilegia os aspectos curativistas em detrimento da abordagem pautada nos princípios da integralidade, humanização e autonomia do sujeito ${ }^{4}$. Cabe destacar a emergência do modelo higienista, representado na teia pelos significados concernentes aos cuidados de higiene corporal realizados na escola. Sob essa ótica os resultados destacaram as abordagens prescritivas depositário-bancárias e as condutas voltadas para a "normatização" e "docilização" dos corpos, responsabilização/culpabilização individual e controle das "vontades e dos desejos" por intermédio da padronização e coerção disciplinar dos hábitos e costumes sociais. Segundo Focault $^{23}$, isto fabrica corpos submissos tornando-os alvo de mecanismos de poder ao estabelecer elos entre aptidão e dominação; e, produz dissociação no biopoder, pois acentua aptidão e capacidade e atenua energia e potência gerando relação de sujeição estrita ${ }^{23}$.

Essa teia representa os significados que foram atribuídos pelos escolares a partir de sua leitura do atual modelo hegemônico de saúde. Em qualquer lugar da teia (em cujo centro estão as práticas de saúde focadas na doença), os significados estão entrelaçados influenciando e sendo influenciados mutuamente uns pelos outros, mantendo o padrão cultural que estrutura as práticas de saúde na escola e repercute de diferentes maneiras no cuidado dos escolares.

$O$ que queremos enfatizar em relação à dinâmica existente entre os diversos significados atribuídos pelos escolares é que, por exemplo, ao partir do termo "doença" a mesma pode ser entendida pelos sujeitos como ligada inicialmente ao lugar onde é tratada ("Hospital") e aos pro- 
fissionais que dela cuidam ("Figura do médico e da enfermeira"). Contudo, outros pontos da teia são afetados por essa mesma linha de significação quando, por exemplo, o local e os profissionais que tratam da doença são correlacionados ao tratamento ("Dor, sofrimento e morte") ou ao conjunto de orientações fornecidas para o cuidado de sua saúde ("Normatização do corpo"). Pode-se inferir que os significados acerca das práticas de promoção da saúde são culturalmente apreendidos desde a infância, sendo constantemente reelaborados e reproduzidos durante toda a vida, porém mantendo certo padrão. Daí decorre a perpetuação da visão medicalizante da nossa sociedade. Por outro lado, na Figura 5 encontram-se ilustrados os significados atribuídos às práticas de promoção da saúde a partir dos anseios e necessidades da comunidade escolar. Nessa segunda teia, a centralidade das ações de saúde é representada por significados relacionados às questões distintas da teia anterior e mais voltadas às relações interpessoais, meio ambiente, lazer, entre outros. As produções simbólicas realçaram o papel da família, comunidade e relações sociais em detrimento do hospital e dos serviços de saúde, dando ênfase aos sentimentos e interações humanas. Os escolares relacionaram a saúde com o bem-estar psicossocial, caracterizado pelo realce dos sentimentos positivos (sorrir, brincar, sentir paz e tranquilidade) e pela importância da amizade e cuidado pela natureza e pelo ser humano. O cotidiano foi retratado pelos jogos de futebol, encontros na praça e sensações agradáveis oriundas desses momentos, em que pese o papel relevante desses aspectos na construção da significação do tema saúde.

Os significados atribuídos pelas crianças se configuram como possíveis expectativas que pontam para um outro modelo de atenção que abarque plenamente as necessidades da coletividade em que vivem. Da mesma forma que na teia anterior, percebeu-se a interligação de cenários como a praça e parquinho com os equipamentos utilizados pelos escolares ("Gangorra, balanço, escorrega") e as interações sociais com outros agentes ("Colegas da turma"). Essas interações sociais ("Experiências pessoais e coletivas") ao produzirem experiências positivas geram sentimentos de tranquilidade, paz, alegria e consequentemente bem-estar oriundos da dinâmica

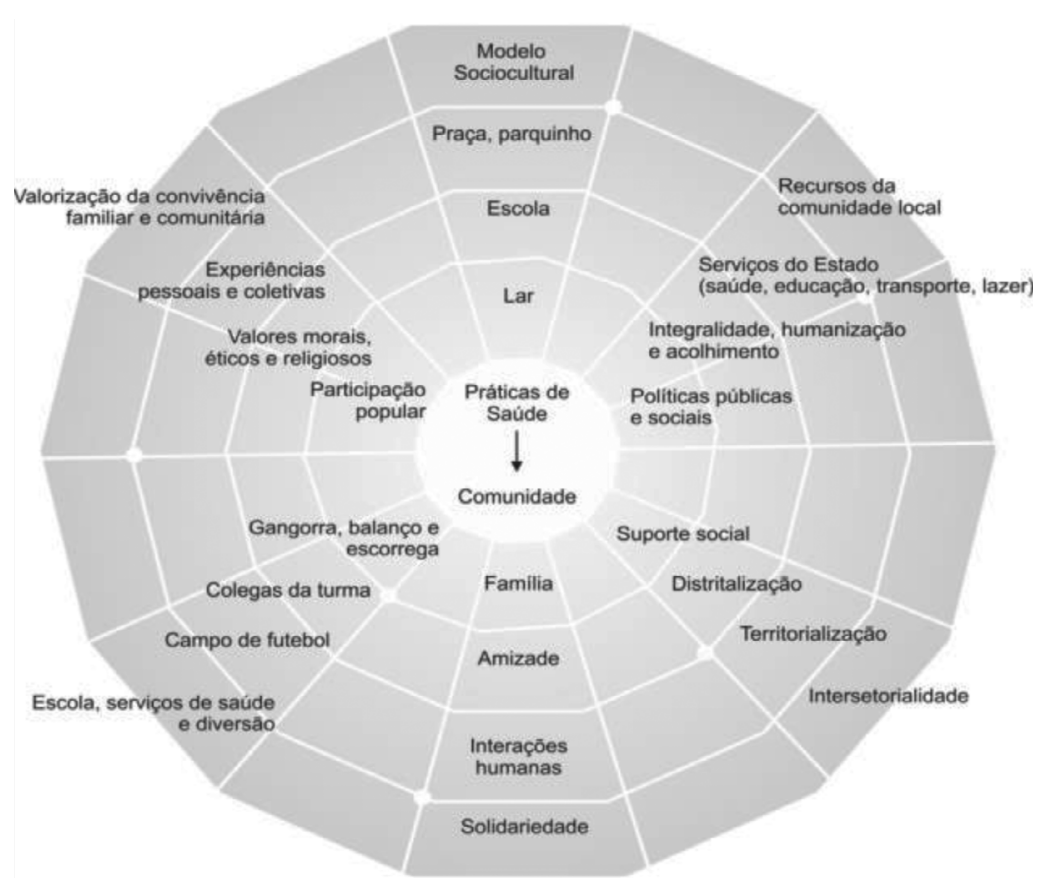

Figura 5. A ressignificação das práticas de promoção da saúde pelos escolares. 
de valorização da convivência familiar/comunitária. A ressignificação com base nos achados desse estudo foi possível haja vista que os sujeitos puderam interagir com os significados, perceber e avaliar seus anseios e necessidades a partir dos padrões culturais que estruturam as práticas de promoção da saúde na escola. Certamente esses escolares têm o potencial necessário para se tornarem agentes ativos de mudança, na medida em que tal potencial seja devidamente trabalhado. A emergência desses significados minoritários concernentes ao modelo dos determinantes sociais de saúde permite questionar o papel do Estado na implementação de políticas públicas que potencializem efetivamente o empoderamento dos usuários do SUS e redução das desigualdades com vistas à melhoria da qualidade de vida da população.

\section{Considerações finais}

A escola é considerada um espaço ímpar de relações sendo ideal para o desenvolvimento e fortalecimento do pensamento crítico e político, pois nas suas metas estão incluídos a construção de valores pessoais, crenças, conceitos e maneiras de conhecer o mundo, de forma a interferir dire- tamente na produção social da saúde. É possível concebermos que a saúde dos adultos começa a ser construída a partir da perspectiva destes quando eram ainda crianças, e por isso, para que uma sociedade seja composta com uma população adulta predominantemente saudável, é de extrema importância que a educação para a saúde tenha seu marco inicial ainda infância.

Precisamos como profissionais de saúde aprender a ouvir a voz das crianças. Isto é essencial para o fortalecimento do vínculo tornando mais efetivo as práticas de promoção da saúde. É nesse sentido que a presente investigação trouxe para o debate científico, questões ainda pouco exploradas no campo da saúde coletiva, em especial, na área de saúde do escolar evitando-se com isso, qualquer aproximação com a perspectiva adultocêntrica. No que tange à formação acadêmica e produção de conhecimentos, estes devem ser voltados para sua efetiva inserção no cenário escolar, em que pese as diferentes realidades regionais. Um caminho possível para viabilização desse processo perpassa pela implementação permanente de ações extensionistas, numa perspectiva dialógica, implicando na busca de parcerias locais com a comunidade escolar que estejam mais mobilizados para a articulação das condições necessárias ao movimento de mudança.

\section{Colaboradores}

EAJCF Lucas participou de todas as etapas da pesquisa e elaboração do manuscrito (autor da tese). RCF Adorno participou como orientador da tese e na elaboração e revisão crítica do manuscrito. AEV Santos participou na elaboração e revisão crítica do manuscrito. MAR Tyrrell participou na revisão crítica do manuscrito. VLRC Halfoun participou na revisão crítica do manuscrito. 


\section{Referências}

1. Geertz C. A Interpretação das Culturas. Rio de Janeiro: LTC; 2011.

2. Sociedade Brasileira de Pediatria (SBP). Departamento Científico de Saúde Escolar. Cadernos de Escolas Promotoras de Saúde [Internet]. [acessado $2020 \mathrm{fev} 20$ ]. Disponível em: http://www.bvsde.paho.org/bvsacd/ cd57/cadernosbpfinal.pdf.

3. Sarmento MJ. Conhecer a infância: os desenhos das crianças como produções simbólicas. In: Martins Filho AJ, Prado PD. organizadores. Das pesquisas com crianças à complexidade da infância. Campinas: Autores Associados; 2011.

4. Brasil. Ministério da Saúde (MS). Secretaria de Atenção à Saúde. Departamento de Atenção Básica. Passo a passo PSE (Programa Saúde na Escola) - Tecendo caminhos da intersetorialidade. Brasília: MS, 2011.

5. Brasil. Decreto $n^{\circ}$ 6.286, de 5 de dezembro de 2007. Institui o Programa Saúde na Escola - PSE, e dá outras providências. Diário Oficial da União 2007; 6 dez.

6. Coelho MTÁD, Almeida Filho N. Análise do conceito de saúde a partir da epistemologia de Canguilhem e Foucault. In: Goldenberg P, Gomes MHA, Marsiglia RMG, organizadores. O Clássico e o Novo: tendências, objetos e abordagens em ciências sociais e saúde. Rio de Janeiro: Fiocruz; 2003.

7. Scliar M. História do Conceito de Saúde. Physis 2007; 17(1):29-41.

8. Laburthe-Tolra P. Warnier JP. Etnologia-antropologia. 5 a ed. Petrópolis: Vozes; 2010.

9. Minayo MCS. Estrutura e sujeito, determinismo e protagonismo histórico: uma reflexão sobre a práxis da saúde coletiva. Cien Saude Colet 2001; 6(1):7-19.

10. Elias N. Teoria Simbólica. Oeiras: Celta; 1994.

11. Muller F. Infâncias nas Vozes das Crianças: Culturas Infantis, Trabalho e Resistência. Educ Soc 2006; 27(95):553-573.

12. Minayo MCS. O desafio do conhecimento: pesquisa qualitativa em saúde. $8^{\mathrm{a}}$ ed. São Paulo, Rio de Janeiro: Hucitec, Abrasco; 2004.

13. Fontes RS. Estudo colaborativo: uma proposta de ação inclusiva. Araraquara: Junqueira \& Marin; 2009.

14. Gil AC. Como Elaborar Projetos de Pesquisa. $4^{\text {a }}$ ed. São Paulo: Atlas; 2007.

15. Menezes M, Moré CLOO, Cruz RM. O desenho como instrumento de medida de processos psicológicos em crianças hospitalizadas. Aval Psicol 2008; 7(2):189198.

16. Chizzotti A. Pesquisa em ciências humanas e sociais. São Paulo: Cortez; 2009.
17. Adorno RCF, Castro AL. O exercício da sensibilidade: pesquisa qualitativa e a saúde como qualidade. Saude Soc 1994; 3(2):172-185.

18. Cyrino EG, Pereira MLT. Reflexões sobre uma proposta de integração saúde-escola: o projeto saúde e educação de Botucatu, São Paulo. Cad Saude Publica 1999; 15:S39-S44.

19. Baggio MA, Berres R, Gregolin BPS, Aikes S, Baggio MA, Berres R. Implantação do Programa Saúde na Escola em Cascavel, Paraná: relato de enfermeiros. Rev Bras Enferm 2018; 71:1540-1547.

20. Souza EFD, Soares MCS, Santos SFS, Paulo TRS, Brandão MVS, Freitas Júnior IF. Construção de modelo lógico na saúde do escolar: experiência do Baixo Amazonas. Rev Bras Enferm 2018; 71(3):1198-1202.

21. Gomes LC. O desafio da intersetorialidade: a experiência do Programa Saúde na Escola (PSE) em Manguinhos, no Município do Rio de Janeiro [dissertação]. Rio de Janeiro: Escola Nacional de Saúde Pública Sergio Arouca; 2012.

22. Buss PM, Pellegrini FA. A saúde e seus determinantes sociais. Physis 2007; 17(1):77-93

23. Foucault M. Vigiar e punir: nascimento da prisão. $42^{\mathrm{a}}$ ed. Petrópolis: Vozes; 2016.
Artigo apresentado em 04/10/2019

Aprovado em 12/07/2020

Versão final apresentada em 14/07/2020

Editores-chefes: Romeu Gomes, Antônio Augusto Moura da Silva 